\title{
ORIENTACIÓN Y ATENCIÓN A LA DIVERSIDAD: DESCRIPCIÓN DE PROGRAMAS Y ACCIONES EN ALGUNOS GRUPOS EMERGENTES
}

\section{(Counseling and attention for the diversity: description of programs and actions in some emerging groups)}

\author{
por
}
Article Record
$\underline{\text { About authors }}$
$\underline{\text { HTML format }}$

\author{
Agustín Bayot (Agustin.Bayot@uclm.es), \\ Benito del Rincón (B.Rincon@uclm.es) y
}

Fuensanta Hernádez Pina (fhpina@um.es) ficha del articulo

$\underline{\text { Sobre los autores }}$

Formato HTML

\section{Abstract}

This article offers points for reflection, practical elements and criteria for adoption in relation to addressing diversity and its orientation. Formal and informal contexts are dealt with from a social and educational perspective; the diversity which can be found in the ordinary population and those included within the so called "emerging groups" are also focused on.

Within this framework the function of the educational psychologist lies not only in knowing the basic characteristics of the groups which most represent diversity and in evaluating specific situations, but also in bringing solutions to the problems specific to each group, both as individuals and as a collective, by means of the creation and application of programmes of intervention. Our contribution concentrates on the description of the problems presented by certain groups and proposing effective plans for action.
\end{abstract}

\section{Keywords}

Addressing diversity, emerging groups, counselling, programmes of intervention

\section{Resumen}

Este artículo quiere ofrecer líneas de reflexión, criterios a seguir y elementos prácticos acerca de la atención a la diversidad y a su orientación. La temática se abordará desde una perspectiva social y escolar, contemplando a la vez contextos educativos formales y no formales y atendiendo "las diversidades" que podemos encontrar en la población ordinaria y las que se podrían incluir bajo el epígrafe de "grupos emergentes".

En este marco, la función del psicopedagogo no sólo radica en conocer las características básicas de los grupos más representativos que conforman la diversidad y en evaluar situaciones concretas sino fundamentalmente en aportar soluciones a los problemas relativos a cada grupo, tanto de forma individual como colectivamente, por medio de la elaboración y aplicación de programas de intervención. Nuestra aportación se centrará en describir la problemática que presentan determinados colectivos así como en plantear líneas de actuación eficaces

\section{Descriptores}

Atención a la diversidad, grupos emergentes, orientación, programas de intervención 


\section{Introducción}

En estos últimos años, la diversidad en sus múltiples manifestaciones ocupa la atención y el discurso de los responsables sociales y educativos por varias causas: la presencia creciente en nuestro estado, y en los países occidentales en general, de población étnicamente diferente; el compromiso político-social de ofrecer igualdad de oportunidades a todas las personas, independientemente de sus características físicas, psíquicas o de su procedencia social y, por último, la convergencia de todos los alumnos en una única etapa educativa hasta los dieciséis años, en la que se ha hecho patente, de forma natural y evidente, la diversidad.

Por último, es obligado mencionar que los problemas éticos generados a partir de la mayor o menor tolerancia y respeto a las diferencias entre las personas, han provocado conflictos de difícil solución y que, en todo caso, han incrementado la actualidad del tema que nos ocupa.

\section{La diversidad}

Las personas somos diferentes por razón de nuestra herencia, intereses, motivaciones, ritmos de aprendizaje, grupo social de procedencia, sexo, expectativas vitales, capacidades sensoriales, motrices o psíquicas, posibilidades y experiencias laborales, lengua e ideología, etc. En la configuración de estas diferencias o "diversidades" han mediado factores genéticos y evolutivos internos pero también, y quizá sobre todo, personas, grupos y ambientes concretos. La diferencia, en sí, enriquece la vida humana y genera complementariedad. Lo verdaderamente empobrecedor es que ese "ser diferentes" desemboque en desigualdad, en falta de equidad y en injusticia social.

Entendemos que los distintos ámbitos educativos atienden la diversidad si parten de las diferencias y las aprovechan para el crecimiento personal y colectivo de los individuos. Las instituciones educativas y la misma sociedad deben ser conscientes de que el proceso de construcción personal depende de las características individuales (de su diversidad), pero sobre todo de los apoyos y de las ayudas que se proporcionen. Sostenemos que la misma diversidad debe formar parte de ese contexto enriquecedor y generador de ayuda. Obviar la diversidad sería tanto como soslayar la singularidad humana y despreciar su riqueza.

Educar en la diversidad supone, en definitiva, pensar en una escuela para todos, en unas posibilidades sociales no excluyentes para nadie y en dar a cada uno el "menú" más conveniente para que consiga avanzar en su crecimiento lo más posible a partir de lo que es y desde donde se encuentra. Supone resolver progresivamente, y en la práctica, dilemas como uniformidad / diversidad y homogeneidad / heterogeneidad.

\section{Atención a la diversidad en los grupos emergentes}

Hemos comentado en el punto anterior que los seres humanos, por propia naturaleza, son intrínsecamente diferentes unos de otros. El problema aparece cuando entre esa diversidad se producen discriminaciones tanto en el ámbito individual como grupal. En el ámbito de grupo, las discriminaciones pueden aparecer entre las personas situadas en la tercera edad, personas con discapacidad, tanto física como psíquica, en los refugiados e inmigrantes y en aquel sector de la sociedad dependiente de alguna sustancia adictiva y en las infecciones por el virus VIH/SIDA.

\subsection{Tercera edad.}

Según el Instituto Nacional de Estadística (INE) (1992), la mitad de la población española alcanza la edad de 77 años. Este hecho conlleva una "nueva cultura" entorno a la vejez. Este cambio en la pirámide poblacional conlleva un fenómeno cada vez de mayor importancia como es el proceso de socialización en las personas mayores. La socialización es el proceso mediante el cual el individuo adquiere aquellas conductas, creencias, valores y motivos que son valorados en su contexto social, familiar, etc. La socialización también hace referencia a cómo dicho proceso llega a generar un control internalizado de la conducta social. 
Bayot, A., Rincón, B. Del y Hernandez Pina, F. (2002): Orientación y atención a la diversidad: descripción de programas y acciones en algunos grupos emergentes . RELIEVE:, v. 8, n. 1, p. 66-87.

http://www.uv.es/RELIEVE/v8n1/RELIEVEv8n1_2.htm

Desde este punto de vista, la conducta depende más de disposiciones internas que de los controles externos, a diferencia de otras etapas en las que el aprendizaje es más importante.

Por otra parte, en este proceso de socialización es básico el estado general en el que se encuentre el anciano/a y su nivel económico. Según el INE (1992), únicamente el $2.27 \%$ de las personas mayores de 65 años se mantiene económicamente activa (es posible que estas cifras vayan modificándose en los próximos años, debido a los cambios que se puedan producir con relación a las prestaciones de la Seguridad Social: trabajo a tiempo parcial, etc.). El 55\% de los españoles vive en pareja, y el $18 \%$ solos. Por lo tanto, el $73 \%$ de las personas mayores de 65 años vive de forma independiente. El 24\% vive con familiares, debido a problemas económicos y físicos. Únicamente el 3\% vive en residencias (INSERSO, 1993). Sin embargo, las relaciones sociales fuera del contexto familiar pueden ser tan importantes como las relaciones familiares, produciéndose el principio de sustitución. Tanto unas como otras son básicas para la socialización y el desarrollo de las personas mayores. Dada la evolución que se ha producido en el sistema familiar actual, el principio de sustitución ha determinado que muchas de las relaciones intenten reproducirse en la comunidad. Por tanto, las relaciones intergeneracionales en la comunidad han pasado a desempeñar un papel socializador muy importante, ya que tiene múltiples efectos beneficiosos sobre la salud y el bienestar (Ishii-Kuntz, 1990).

Estas relaciones sociales se pueden analizar desde cuatro perspectivas interrelacionadas:

a) Relaciones interpersonales. Tanto en la dimensión estrictamente social como afectiva. Son imprescindibles. Generan apoyo social y forman las redes sociales.

b) Redes sociales. Características estructurales de las relaciones.

c) Sistemas de apoyo. Es la provisión de ayuda en el contexto de las relaciones interpersonales (contexto familiar y comunitario). d) Salud/bienestar. Las relaciones sociales disminuyen la probabilidad de institucionalización. Se ejerce un efecto protector.

\subsection{Refugiados e inmigrantes.}

Según la OIT más de 70 millones de personas se encuentran fuera de su territorio en todo el mundo debido a factores económicos, demográficos y/o por falta de libertad en sus países de origen. Esta creciente tendencia a la movilidad hace que el tema de la inmigración sea de especial interés en los países de nuestro entorno. En España el 1,6\% de la población son inmigrantes, en Francia la cifra es de un $8,2 \%$, en Alemania $7,2 \%$, siendo la media europea de un $6 \%$. Se estima que hay unos 800.000 españoles residentes en el extranjero.

Concretamente en España, se estima que viven y trabajan legalmente alrededor de 300.000 inmigrantes extranjeros procedentes en su mayor parte de Latinoamérica y del norte de África, aunque dicha cifra podría duplicarse si consideramos a la población de inmigrantes ilegales sin permiso de trabajo ni de residencia (Bayot, Navarro y Del Rincón, 1999).

Sin embargo, se calcula que un $20 \%$ son inmigrantes asentados con oportunidades semejantes a los nacionales, un $30 \%$ son trabajadores precarios aunque legalizados que ocupan puestos poco atractivos para los nacionales y un $50 \%$ son indocumentados con pésimas condiciones de trabajo.

Por otra parte, hay que añadir que la opinión y el sentimiento que presentan los adultos españoles frente a los inmigrantes no son muy favorables. En la encuesta realizada en 1997 por el IMSERSO, el $46 \%$ opina que contribuyen a aumentar el paro y el $47 \%$ opina que aumenta la delincuencia (Díez, 1998). No obstante, el $20 \%$ de los españoles se considera entre "muy racista" (4\%) y "bastante racista" $(16 \%)$, frente al $33 \%$ de la media europea, el $48 \%$ de los franceses, y el $36 \%$ de los alemanes. Entre los adolescentes, los porcentajes relacionados con las actitudes racistas se in- 
Bayot, A., Rincón, B. Del y Hernandez Pina, F. (2002): Orientación y atención a la diversidad: descripción de programas y acciones en algunos grupos emergentes . RELIEVE:, v. 8, n. 1, p. 66-87.

http://www.uv.es/RELIEVE/v8n1/RELIEVEv8n1 2.htm

crementan; ya que muestran una mayor sinceridad en sus respuestas.

Un aspecto de especial preocupación se centra en la escolarización de los hijos de inmigrantes, tal como se ha puesto de manifiesto en publicaciones recientes (Aguado, Gil, Jiménez-Frías y Sacristán, 1999; Bartolomé, Cabrera, Del Campo, Espín, Marín, Rodríguez, Sandín y Sabariego, 1999; Bartolomé, Cabrera, Espín, Marín y Rodríguez, 1999; Soriano, Moreno, Collado y Martín, 1999). Concretamente en la provincia de Cuenca, residen 113 niños pertenecientes a culturas minoritarias. Una posible solución radica en incorporar en el curriculum escolar programas que fomenten la educación intercultural, programas que se desarrollarán en un apartado posterior.

\subsection{Diversidad cultural}

Decíamos más arriba que la presencia de importantes bolsas migratorias en la mayoría de los países occidentales ha obligado a efectuar replanteamientos ideológicos, éticos, religiosos, educativos, culturales en general y, sobre todo, a pensar las actitudes y las formas de conducta que son más coherentes con las exigencias de una sociedad democrática y no discriminadora. Para avanzar en esa dirección, es necesaria la acción educativa intercultural pues la simple "coexistencia física" de grupos culturales diferentes no genera una convivencia social positiva y enriquecedora. $\mathrm{La}$ inercia o el azar produce asimilacionismos, racismos, guetos, etnocidios, resistencias culturales y religiosas, etc. (Jordán, 1998). Por otra parte, el respeto a la dignidad de la persona implica, lógicamente, respetar el derecho de las distintas comunidades culturales a escoger y practicar su particular forma de vida. Sólo es posible una actitud de interacción y de valoración positiva de otras comunidades culturales si la propia es mínimamente respetada y valorada.

Aún se dan, en mayor o menor medida, y fruto de estereotipos, más que de intencionadas posiciones, actitudes racistas o de hostilidad hacia las personas de un grupo cultural por el hecho de pertenecer a él y porque, superficialmente, se cree que todos los miembros de ese grupo tienen cualidades negativas o inferiores. La educación tiene que favorecer el intercambio, la valoración ecuánime de todas las culturas y el enriquecimiento mutuo.

\subsection{Discapacidades}

Según Rivas (1999), la clasificación de las discapacidades como sensoriales (visuales y auditivas), motóricas y psíquicas resulta en ocasiones demasiado general para varias de esas deficiencias. Ya que existen personas que presentan más de una y, además, es un aspecto que expresa la interacción que experimentan las personas según su relación con el propio medio. En ocasiones, la discapacidad tiene manifestaciones que inciden en el desarrollo intelectual, en la comprensión, en las destrezas y habilidades manuales y espaciales, en la formación de la personalidad y en la socialización (Pelechano, 1995). No obstante, el grado de secuela que la minusvalía genera es la primera barrera con que se encuentran las personas con esta problemática (Rivas, 1999). En el apartado relativo a los programas de intervención, trataremos este aspecto con mayor detalle.

\subsubsection{Disfunción visual.}

A 30 de junio de 1999, el censo de afiliados a la Organización Nacional de Ciegos Españoles (ONCE) es de 57.424 personas. Para estar asociados tienen que presentar una deficiencia del 90\% Por Comunidades Autónomas, en Andalucía se encuentra el número más elevado (13.058); en cambio, La Rioja ocupa el lugar inferior (410). No obstante, se desconoce el número total de personas que presentan una deficiencia visual. Por edades, 865 tienen menos de cinco años y 4.256 tienen una edad que oscila entre los 6 y los 18 años. Por encima de 66 años, el número de ciegos se eleva a 19.494 personas. Por otra parte, hay que señalar que existe una mayor proporción en hombres que en mujeres hasta los 66 años, produciéndose en esta edad una inversión en la tendencia señalada con anterioridad.

Con relación a la situación laboral, el 92.5\% de los afiliados trabaja. EL 86.2 son empleados 
de la ONCE y el resto trabaja fuera de la Organización. El 7.5\% está en paro. Con relación a la escolarización de los niños y adolescentes con disfunciones visuales, más de 8.000 niños y jóvenes se benefician de las ayudas educativas de la Organización.

\subsubsection{Disfunción auditiva}

Aunque se desconoce la existencia en términos absolutos el número de personas con deficiencia auditiva, sí que se ha producido un hecho a tener en cuenta en las dos últimas décadas. Ya que, según Villalba (1999), se ha pasado de ser un hecho infrecuente la asistencia de estudiantes sordos en centros ordinarios de enseñanza secundaria a contar en las distintas facultades de la Universidad de Valencia con 31 disminuidos auditivos. Una de las áreas que se ve más perjudicada es el lenguaje. La calidad del lenguaje oral que puede llegar a alcanzar el deficiente auditivo depende de (Villalba, 1999):

-La edad de aparición de la sordera.

-Restos auditivos conservados.

-Estado neurológico y capacidad del aprendizaje.

-Edad en la que se adaptó el audífono y en la que comenzó el entrenamiento auditivo y logopédico.

-Edad en la que comenzó el implante coclear.

-Rendimiento que obtiene de sus audífonos o de su implante coclear.

-Carácter y personalidad.

-Entorno comunicativo, educativo y familiar.

A partir de la literatura existente al respecto, los problemas emocionales, tales como sentimiento de soledad, baja autoestima, dependencia, inseguridad, impulsividad, etc., son más frecuentes entre los sordos.

\subsubsection{Insuficiencia renal crónica.}

La Insuficiencia Renal Crónica (IRC) se produce por la disminución gradual y progresiva del nivel de filtración de los riñones. Esta disminución gradual y progresiva de la función renal explicaría la ausencia de manifestaciones clínicas iniciales hasta que el proceso no afecta de un 70 a un $80 \%$ del total de las nefronas (unidades funcionales del riñón) o hasta que el índice de filtración es inferior al 20 ó $25 \%$ de los valores considerados normales.

El trasplante, la hemodiálisis (HD), la diálisis peritoneal continua ambulatoria (DPCA), y la diálisis peritoneal automatizada (DPA) son técnicas que permiten a las personas cuyos riñones no cumplen su función, seguir llevando una vida relativamente normal.

Según la Asociación para la Lucha Contra las Enfermedades Renales (ALCER), 17.483 personas adultas en España padecen una insuficiencia renal crónica. Este dato representa el 440.8 por millón de habitantes. Entre ellos, únicamente 3.850 se encuentran en lista de espera de un transplante de riñón (97.1 por millón de habitantes). Sin embargo, el dato más dramático hace referencia a que 87 niños de corta edad se encuentran sometidos a este tratamiento para poder seguir con vida. Más de la mitad, concretamente 47, se encuentran en lista de espera para un posible trasplante renal.

Analizando el grupo de pacientes con menos de 65 años, únicamente el 18\% tiene alguna ocupación laboral. Aún teniendo en cuenta el carácter limitador de la enfermedad renal, el nivel de ocupación es realmente bajo (ALCER, 1997). Este hecho también se produce en la escolarización de los niños. Ya que la gran mayoría no puede asistir a clase. No obstante, aunque se han habilitado profesores de apoyo, es a todas luces insuficiente. Por lo tanto, el problema a largo plazo no va a ser la enfermedad sino la falta de formación para ocupar puestos de trabajo. Una vez más hay que incidir en la formación (aspecto al que volveremos posteriormente). Es más, la Asociación Europea de Pacientes Renales (CEAPIR) considera este aspecto como uno de los 12 objetivos prioritarios (derecho de todos los pacientes renales 
Bayot, A., Rincón, B. Del y Hernandez Pina, F. (2002): Orientación y atención a la diversidad: descripción de programas y acciones en algunos grupos emergentes . RELIEVE:, $v .8$, n. 1, p. 66-87.

http://www.uv.es/RELIEVE/v8n1/RELIEVEv8n1_2.htm

a la rehabilitación y acceso al trabajo), en el ámbito europeo, de las personas con IRC.

\subsubsection{Parálisis cerebral.}

La parálisis cerebral infantil forma parte de las discapacidades motóricas, tomando como base la clasificación realizada por el Centro Nacional de Recursos para la Educación Especial (CNREE) (cuadro 1).

Según Ferrer y Alcantud (1999), una definición operativa fue la descrita en 1966 en el Congreso de Berlín y ratificada en 1969 en el Congreso de Edimburgo sobre Parálisis Cerebral: "Desorden permanente y no inmutable de la postura y del movimiento, debido a una disfunción del cerebro antes de completar su crecimiento y su desarro1lo" (Cahuzac, 1985). Aparte de otros problemas relacionados con la enfermedad, se producen retrasos de hasta dos años en la aparición de la lectura. Este hecho se produce por la acción de varios factores, tales como dificultades en el aprendizaje del habla y el lenguaje, escolarización anómala, problemas perceptuales, etc. (Ferrer y Alcantud, 1999). Aproximadamente el $75 \%$ de los niños con parálisis requieren una reeducación logopédica (Basil, 1996).

Respecto de la evaluación psicopedagógica, a pesar de la diversidad de los casos y su posible generalización a las demás disfunciones motóricas, las áreas en las que, quizás, habría que poner un mayor énfasis serian las siguientes: a) el lenguaje; b) la motricidad; c) el área personal; d) el área adaptativa (incluyendo control de esfínteres, aseo personal, etc.) y e) el área cognitiva.

Cuadro 1. Clasificación de las deficiencias motrices del CNREE (citado en Ferrer y Alcantud, 1999).

1) Origen cerebral

a) Parálisis Cerebral.

b) Traumatismos Craneoencefálicos.

c) Tumores.

2) Origen espinal

a) Poliomielitis anterior aguda.

b) Espina bífida

c) Lesiones medulares degenerativas.

3) Origen muscular

Miopatías (Distrofia muscular de Duchenne, distrofia de Landuzy-Dejerine, ...).

4) Origen óseo-articular

a) Malformaciones congénitas: amputaciones congénitas, luxación congénita de caderas, $\ldots$

b) Distróficas: condodistrofia, osteogénesis imperfecta,...

c) Microbianas: osteomielitis aguda, tuberculosis óseo-articular,...

d) Reumatismos de la infancia: reumatismo articular agudo, reumatismo crónico,...

e) Lesiones osteoarticulares por desviaciones de la columna: cifosis, lordosis, escoliosis. 
Bayot, A., Rincón, B. Del y Hernandez Pina, F. (2002): Orientación y atención a la diversidad: descripción de programas y acciones en algunos grupos emergentes . RELIEVE:, v. 8, n. 1, p. 66-87.

http://www.uv.es/RELIEVE/v8n1/RELIEVEv8n1_2.htm

\subsection{Dependencia a sustancias adictivas}

El tabaco, la heroína y el alcohol son las substancias adictivas que mayores problemas de salud acarrean en la sociedad actual. Por lo tanto, únicamente nos centraremos en estas conductas adictivas.

\subsubsection{Heroína.}

Según la Fundación de Ayuda contra la Drogadicción (FAD, 1997), existen claras evidencias sobre la disminución de consumidores problemáticos de heroína. Este hecho se fundamenta en los siguientes aspectos: a) el número de personas admitidas a tratamiento ha pasado de 20.017 en 1992 a 12.993 en 1997; b) las cantidades de heroína decomisadas han descendido desde 886 $\mathrm{Kg}$ en 1990 a 479 en 1997; c) ha descendido el número de muertes provocadas por reacción aguda a la droga y d) aumenta la edad media de los consumidores, así como la edad de inicio en el consumo de dicha droga.

En 1997 la red de recursos específicos de atención para drogodependientes del Plan Nacional sobre Drogas, públicos o privados con financiación pública, ha experimentado un importante desarrollo gracias, fundamentalmente, a los programas de mantenimiento con metafonía. Dichos programas han continuado la tendencia de crecimiento, tanto en el número de centros, 894 (prescriptotes, dispensadores y prescriptores/dispensadores), como en el número de usuarios atendidos: 55.813. No obstante, se desconoce el número exacto de personas adictas a la heroína, ya que pueden estar inscritos en diversas comunidades al mismo tiempo.

Respecto del perfil del heroinómano, éste se sitúa entorno a los 30/40 años. Su adicción se inicia en la adolescencia; de esta forma se interrumpe todo el proceso educativo, con las consecuencias negativas que este hecho acarrea a largo plazo. No forman parte de redes de trabajo estable. Subsisten de la asistencia social y de la familia. Una posible vía de solución se encuentra en la planificación de programas de prevención y de reinserción. Fundamentalmente, existen dos tipos de intervención: a) programas de metadona y b) programas de deshabituación.

\subsubsection{Alcohol}

Según la "Encuesta domiciliaria sobre el consumo de drogas" (FAD, 1997), un $60.7 \%$ de los españoles entre 15 y 65 años consumieron alcohol durante los 30 días previos a la encuesta; un $12.9 \%$ lo hacía diariamente y un $9.3 \%$ se había emborrachado alguna vez durante el último año. La mayor proporción de consumidores mensuales se sitúa entre los 19 y los 28 años, con un $68.9 \%$ Además, un $43 \%$ de la población entre los 15 y los 28 años, mantiene un patrón de consumo de fin de semana. En cambio, el consumo diario se sitúa entre los mayores de 49 años.

\subsubsection{Tabaquismo}

El tabaquismo está reconocido como uno de los problemas más importantes de salud pública. Concretamente en Europa, se calcula que se producen 800.000 muertes anuales debido al consumo de tabaco (Steptoe, Wardie, Smith, Kopp, Skrabski, Vinck y Zotti, 1995). Es más, se calcula que a mitad del siglo XXI, se producirán en el mundo 10 millones de muertes anuales, atribuidas directamente a los efectos producidos por el tabaco (Bayot, 1994, 1998; Lando, 1991).

En términos generales, la edad de inicio se sitúa entre los 14 y los 16 años (Bayot, 1998). No obstante, algunos estudios indican un inicio en edades más tempranas. Además, actualmente se produce una inversión en el consumo de tabaco entre chicos y chicas: mientras los chicos empiezan a una edad más temprana, las chicas superan el porcentaje de consumo de cigarrillos, con las consecuencias negativas que este hecho acarrea a largo plazo.

En líneas generales, se confirma el lento descenso de la proporción de fumadores diarios en el conjunto de la población de 15-65 años, que ha pasado de 34,7\% en 1995 a 32,9\% en 1997 (FAD, 1997). 


\subsection{Infección por VIH/SIDA}

Según el Centro Nacional de Epidemiología (C.N.E., 1999), desde 1981, año en el que comenzó la epidemia, se han acumulado un total de 55.711 casos de SIDA. En el 53,3\% de ellos se ha notificado ya su fallecimiento. El número de casos diagnosticados en 1998 asciende a 3.195, de los cuales, el 79\% son hombres y la edad media es de 36,4 años.

La vía de transmisión más frecuente ha sido el compartir material de inyección para la administración parenteral de drogas $(58,8 \%)$, lo que se confirma tanto en hombres (59\%) como en mujeres $(57 \%)$. La transmisión por relaciones heterosexuales no protegidas asciende al $20 \%$, pero adquiere especial relevancia en las mujeres, donde representa el 34\% de los casos. La tercera vía de transmisión más frecuente son las prácticas sexuales no protegidas entre hombres $(12 \%$ de los casos).

La tasa de incidencia de SIDA en España en 1998 se estima en torno a 9 casos nuevos por 100.000 habitantes. En todas las Comunidades Autónomas se detectan descensos importantes en el número de nuevos diagnósticos en los últimos años, pero se mantienen las grandes diferencias geográficas con las tasas más elevadas en Madrid, Baleares y el País Vasco.

La prevención sigue siendo en la actualidad el aspecto más importante para atajar las graves consecuencias de dicha enfermedad. Por lo tanto, los programas de intervención tendrían que estar orientados a producir cambios en las actitudes de los individuos para que se modificaran los comportamientos de riesgo, como se ha puesto de manifiesto en un trabajo anterior (Bayot y Mari, 1998).

\section{Perspectivas psicopedagógicas de aten- ción a la diversidad}

Enseñar y aprender la diversidad de la especie humana es una de las tareas fundamentales de la educación para el siglo XXI (Delors, 1996). La diversidad es un fenómeno que constatan (constatamos) diariamente todos los educadores. Así, por ejemplo, vemos al padre o a la madre expresar con sorpresa el hecho de que sus hijos sean tan distintos, siendo que han vivido en el mismo ambiente y han tenido una influencia educativa similar. El monitor de tiempo libre comenta frecuentemente que, ante la misma propuesta lúdica, obtiene respuestas variadas que oscilan entre el entusiasmo y el desánimo. Por último, el profesor escolar se queja de la diversidad, tan patente entre sus veinticinco o treinta alumnos, y procura encontrar aspectos comunes para agruparlos y poder reducir así la variedad de sus propuestas.

La acción educadora tiende, frecuentemente, a uniformizar y se resiste a contemplar las diferencias por varios motivos:

a) Pensar que los demás pueden ser, pensar, actuar,... de forma distinta a como nosotros somos, pensamos y actuamos es un ejercicio que ni todos, ni siempre estamos dispuestos a realizar.

b) La uniformidad ofrece seguridad y sensación de poder al educador. Por el contrario, si entre las personas de un grupo se hace patente la diversidad, los individuos de un grupo realizan actividades distintas al mismo tiempo o se respetan intereses y ritmos, es fácil que el responsable del grupo se inquiete y ponga en duda el aprovechamiento de sus educandos.

c) Existe, y a menudo prevalece, el deseo de simplificar en forma de "propuesta única" sobre la diversificada porque aquélla es menos costosa: en lo metodológico, en cuanto al contenido y organizativamente.

Sin embargo, la labor educadora crece en calidad, pero también en complejidad, a partir del momento en que desea mostrarse respetuosa con la diferencia y cuando procura dar una respuesta educativa adecuada que contemple esa diferencia. La construcción de un programa educativo que atienda a la diversidad tiene que incluir, al menos, tres componentes educativos: 
a) Fomentar el respeto por la diferencia y el saber convivir con los demás, ya sea en el ámbito familiar, social o escolar.

b) Aprovechar esa misma diversidad existente como elemento formativo de los individuos.

c) Ser lo suficientemente flexible, de manera que parta de esa diversidad (o diversidades) y construir, en cada uno y en su conjunto, hasta el máximo de sus posibilidades.

Si la intervención educativa se produce en las tres dimensiones de forma coherente y coordinada, la diversidad habrá sido ocasión para el trabajo en valores, se habrá transformado en contenido educativo y será un magnífico estimulante de actualización y mejora de la propia actuación docente. La diversidad, o las diversidades, habrán dejado de ser un estorbo para convertirse en un medio de extraordinario potencial educativo.

Como ejemplos ilustrativos de estas últimas reflexiones podemos recordar aquí el precioso intercambio educativo que tiene lugar entre los componentes de una familia en la cual, uno de sus miembros, posee una disminución sensorial significativa: crece el respeto y la solidaridad, los individuos aprenden que la dignidad de las personas no depende de su diversidad y los padres van siendo cada vez más conscientes de que las exigencias deben ser proporcionales a los ritmos de aprendizaje de cada uno. El mundo del trabajo $\mathrm{y}$, por consiguiente, la inserción laboral de los jóvenes tiene que contar, cada vez más, con los tradicionalmente excluidos por razón de sus características físicas o psíquicas, de manera que la empresa sea, cada vez, un espacio de formación permanente y de integración social [1]. Por otra parte, si las instituciones educativas regladas quieren seguir cumpliendo su papel democratizador de la cultura, cada vez más tendrán que adecuar sus planteamientos a las numerosas diversidades emergentes o progresivamente más explícitas en los centros educativos.

Los temas de trabajo tratados son los clásicos en la labor psicopedagógica. Resaltar que un alumno con problemas no implica nuevas áreas de trabajo, únicamente exige movilizar la creatividad del profesional para la búsqueda de nuevas respuestas ante demandas propias de su responsabilidad.

En justo reconocimiento de los educadores y de quienes les prestan alguna modalidad de apoyo o asesoramiento, afirmamos que se han producido avances sustanciales: hemos crecido en respeto a las minorías, en algunos centros educativos se intenta ir más allá de la integración para conseguir la inclusividad, ya son muchos los minusválidos que tienen un puesto de trabajo y empieza a preocupar la sobredotación como fenómeno escaso pero que necesita respuestas diferenciadas.

Sin embargo, sabemos también que aún queda mucho por avanzar porque las inercias adquiridas y las experiencias vividas por los educadores tienen un peso específico importante y porque, en el fondo, la aplicación de medidas de atención a la diversidad es también un problema de actitudes. Más concretamente, de cambio de actitudes, tal como planteábamos más arriba. Una de las tareas que puede abordar un psicopedagogo es, precisamente, la de favorecer el cambio de actitudes en los formadores a su cargo. La tarea es tan ardua como entusiasmante $\mathrm{y}$, a nuestro entender, debe pasar por sugerencias como las siguientes:

a) Información. Conocer de qué estamos hablando cuando tratamos de diversidad, cuáles son los planteamientos actuales sobre el tema y en qué situación se encuentran las personas que poseen algún tipo de diversidad menos aceptado o admitido socialmente. En esta misma línea, parece conveniente conocer experiencias de otros educadores que con recursos parecidos y con dificultades equiparables han llevado a cabo propuestas válidas y progresistas.

b) "Vivir" alguna experiencia, aunque pequeña de atención a la diversidad cuyo resultado haya mejorado en algún sentido el trabajo educador. Las innovaciones generan otras innovaciones y las experiencias positi- 
vas crean expectativas en favor de nuevas experiencias.

c) La estructuración de un grupo de educadores empeñados en mejorar sus propuestas en coherencia con la diversidad. En este apartado podemos distinguir:

- Seminarios monográficos en donde un grupo de profesionales se dediquen a profundizar un aspecto de la diversidad desde una perspectiva teórico-práctica.

- Grupos de trabajo implicados en la elaboración de materiales que sean especialmente útiles para atender mejor las minorías étnicas, las personas con minusvalías, etc.

- Profesionales asesorados por especialistas en psicología y pedagogía que avancen, desde el análisis de la propia práctica en procesos de investigación-acción.

Las medidas que favorezcan la atención a la diversidad en los distintos espacios educativos tienen que enmarcarse en dinámicas más globales de innovación en los centros educativos, aunque pueden dificultar estas acciones la falta de incentivos por el hecho de innovar, el trabajo suplementario que representa para los educadores y la falta de tiempo para coordinarse y establecer canales efectivos de comunicación (Parcerisa, 1999 , p. 62). En realidad, se trata de salvar impedimentos actitudinales y, en parte, organizativos que la institución debe tener en cuenta en su planificación general.

La labor de los supuestos asesores, desde la perspectiva que venimos comentando, se orientaría a colaborar con los educadores para que cada uno aporte, desde su formación peculiar, conocimientos, vivencias, puntos de vista, etc., para el desarrollo de actividades concretas propiciadoras de la diversidad y de un clima respetuoso con la peculiaridad de cada individuo. El psicopedagogo es, en definitiva, agente de cambio que impulsa la institución hacia el logro de soluciones y propuestas preventivas o que eviten la aparición de problemas (Del Rincón, 1998).
Así, por ejemplo, la aplicación de un programa de educación en valores suele activar capacidades muy relacionadas con la tolerancia, ponerse en el lugar de los demás, no discriminación, cooperación y otras muchas que se relacionan, en definitiva, con una convivencia más armónica. Los sujetos que frecuentan el contexto de aplicación del citado programa estarán más preparados para relacionarse con individuos caracterizados por alguna "diversidad" poco habitual en el grupo ordinario; raza distinta, discapacidad manifiesta, etc.

El psicopedagogo, en su toma de decisiones relacionadas con la atención a la diversidad en distintos contextos educativos, deberá tener en cuenta algunos criterios generales (Echeita, 1997):

- Tendencia a la máxima normalidad (propuestas lo más cercanas posible al currículum ordinario) y máxima atención individual.

- Procurar que se lleven a cabo medidas ordinarias antes que extraordinarias.

- Facilitar acuerdos de centro respecto al momento en que será necesario aplicar medidas extraordinarias.

- Prever las consecuencias que va a tener la aplicación de medidas extraordinarias para: los alumnos, el propio equipo educativo y la institución.

Frecuentemente, las decisiones curriculares y organizativas tendrán que ir acompañadas de una evaluación específica, realizada por el psicopedagogo, que tendrá muy en cuenta las aportaciones del profesorado.

Desde hace algunos años, han proliferado los servicios psicopedagógicos en contextos universitarios [2], quedando bien de manifiesto la importante función que desempeñan ante las demandas de ayuda del alumnado. En la modalidad de información y orientación académica y profesional, podemos citar el Servicio de Orientación Universitaria (SOU), de la Universitat de Barcelona y el Servicio de Información 
al Estudiante (DISE), de la Universitat de València. Respecto del asesoramiento vocacional de estudiantes con minusvalías, mencionamos, por ejemplo, el Plan de Actuación de la Universitat Jaume I con los Estudiantes con Necesidades Educativas Especiales y el Centro Universitario de Asesoramiento al Estudiante con Discapacidad de la Universitat de València. Por último, hay que destacar la labor sobre prevención e intervención en conductas adictivas que se está llevando a cabo en el Instituto de Investigación sobre Drogodependencias en la Universidad "Miguel Hernández".

Estas actuaciones constituyen sólo una muestra de las múltiples posibilidades que se pueden desarrollar en un contexto universitario. En este sentido, se ha venido desarrollando durante el curso académico 1999/2000, como una experiencia piloto, el Servicio de Orientación Universitaria de Cuenca (SOUC) (Bayot, Del Rincón, Racionero y González, 2000; Del Rincón, Bayot, García y Argudo, 2000).

\section{Necesidades educativas de los grupos emergentes}

\subsection{Minorías culturales}

La realidad multicultural afecta de lleno a nuestra sociedad, pero la educación que impartimos no es todavía intercultural. Ésta última, trataría de "formar en todos los alumnos, de todos los centros, una competencia cultural madura" (Jordán, 1998: 47). Por tanto, la necesidad de una educación para el interculturalismo no afecta sólo a las personas que provienen de otros países, sino que debe ocuparse también de preparar a la población autóctona para desenvolverse con madurez en nuestro contexto, es decir, con capacidad para resolver posibles conflictos, enriquecerse al contacto con otras culturas, juzgar la propia menos egocéntricamente, etc.

\subsection{Deficiencia auditiva}

Las necesidades educativas de este sector de población tienen que ver con la riqueza comuni- cativa de los contextos donde se desenvuelven (Marchesi y Díaz-Estébanez, 1997). En cuanto a la modalidad más conveniente de escolarización, no hay respuesta única: habrá que considerar, sobre todo, las posibilidades de acceso al currículum y de interacción con sus iguales ya que la adaptación social ocupa un lugar clave en el proceso educativo del individuo.

\subsection{Deficiencia visual}

Las personas con discapacidad visual no conceptualizan lo que significa "ver poco" ya que no saben lo que es ver bien; además, tratan de suplir con otros sentidos su deficiencia. Sus avances dependen, en buena parte, del trabajo de estimulación y de interpretación de la imagen. Cuanto más normalizadores sean los entornos educativos, siempre que se atiendan las necesidades específicas asociadas a su diferencia, mejor se desarrollará en los distintos ámbitos: emocional, social, cultural, etc.

\subsection{Parálisis cerebral}

Las disfunciones motoras, como la parálisis cerebral, no tienen porque asociarse siempre a déficits cognitivos o trastornos psíquicos. En todo caso, una evaluación psicopedagógica funcional y tendente a precisar soluciones educativas, será muy orientativa en este punto (Basil, Bolea y Soro, 1996). Las limitaciones motoras suelen precisar adaptaciones y ayudas técnicas y, cuando se asocian dificultades de comunicación, pueden optimizarse con rehabilitación y con intervenciones programadas de desarrollo oral. Igual que en los casos anteriores, van a desempeñar un papel fundamental los entornos educativos normalizados y habilitados, con disponibilidad de materiales, con amplias posibilidades de relaciones sociales y con educadores preparados para apoyar y estimular el desarrollo de estos sujetos.

\subsection{Tercera edad}

Con relación a las personas mayores, las necesidades educativas estarán determinadas, fundamentalmente, por los cambios que se producen en diferentes aspectos, tales como las 
aptitudes cognoscitivas, su situación económica, su estado físico, su estado emocional y motivacional, su personalidad, etc. Con relación a las aptitudes cognoscitivas, las personas mayores necesitan más tiempo para analizar la información (memoria sensorial -Craik y Jennings, 1992), disminuye el número de items procesados a medida que avanza la edad (memoria a corto plazo -Vega y Bueno, 1995-) y presentan dificultades para recuperar la información (memoria a largo plazo -Vega y Bueno, 1996-). Además, la inteligencia fluida (capacidad de resolver problemas nuevos sin la influencia de aprendizajes previos), en la línea de Cattell y Horn, va a condicionar el aprendizaje de conceptos nuevos en la vejez. Estos factores, así como la falta de motivación, cambios en la personalidad, hábitos de estudio, entre otros, deben ser tenidos en cuenta en los cursos de formación de las personas mayores.

\subsection{Dependencia a sustancias adictivas e infección por VIH/SIDA}

El consumo de sustancias adictivas está asociado, fundamentalmente en la adolescencia, a variables tales como estrés, afrontamiento, competencia social y auto-eficacia (Bayot, 1998). Tradicionalmente se ha argumentado que un incremento de la información sobre el peligro que entraña ciertas conductas de riesgo (consumo de drogas, mantener relaciones sexuales sin utilizar medidas de protección, etc.) se reducirían determinados comportamientos. No obstante, los resultados obtenidos en determinadas investigaciones indican que el factor determinante no es tanto la información, quizás excesiva en determinados casos, sino el cambio de actitudes. Concretamente Brown y Fritz (1988) encontraron que la correlación entre el conocimiento y las actitudes comportamentales con relación al SIDA entre adolescentes es mínima.

\section{Programas de intervención}

El objetivo de este apartado radica en describir la adecuación que pueda existir entre la disponibilidad de un puesto de trabajo que la sociedad en general oferta y las posibilidades reales, así como su formación, que presentan algunos de los colectivos que se han analizado anteriormente.

Compartimos la opinión de Beltrán (1993), según la cual, todos los seres humanos son modificables. Por lo tanto, la persona que ayudamos en situaciones psicoeducativas es modificable. En este sentido la acción educativa es considerada básicamente como una acción de cambio que habrá que adecuar en cada caso concreto.

La complejidad creciente de las sociedades actuales demanda de los individuos comportamientos, habilidades, recursos, etc. cada vez más selectos. Cuando se trata de conseguir la integración de personas con discapacidades, los distintos contextos laborales exigen una cualificación que, sin dejar de considerar las peculiaridades individuales, apunten a desarrollar las competencias necesarias para una integración socio-laboral con más posibilidades. En este sentido, son numerosos los programas que, con mayor o menor adaptación, pueden ser útiles para una educación funcional [3].

Para que la igualdad de oportunidades educativas sea un hecho, presentan una importancia capital los medios de acceso a la formación de las personas con dificultades en el desplazamiento, la comunicación, etc. (Beltrán y otros, 1993). Nos referimos, por ejemplo, a la supresión de barreras arquitectónicas (ascensores, rampas,...), equipamiento o materiales adaptados o específicos (teclados adaptados, lupas, máquinas de Perkins para escritura en Braille, etc.), complementos y adaptaciones para sujetar materiales de uso, uso de sistemas alternativos para aumentar o complementar la comunicación (lenguaje de signos, comunicación bimodal, palabra complementada, BLISS, $\mathrm{SPC}, \ldots)$.

En nuestro país, el paro es tres veces superior en personas con alguna discapacidad que en la población en general. No obstante, lo lamentable de este hecho, tal como afirma Rivas (1999), es que no está relacionado ni con la capacitación ni con la formación para el em- 
Bayot, A., Rincón, B. Del y Hernandez Pina, F. (2002): Orientación y atención a la diversidad: descripción de programas y acciones en algunos grupos emergentes . RELIEVE:, v. 8, n. 1, p. 66-87.

http://www.uv.es/RELIEVE/v8n1/RELIEVEv8n1_2.htm

pleo. Concretamente en la Comunidad Valenciana, únicamente el 5.3\% de las personas que presentan algún déficit tienen una formación universitaria. Si nos ceñimos en la Universidad Jaume I de Castellón, durante el curso académico 1997/98, 60 estudiantes presentaban algún tipo de déficit, estando distribuidos de la siguiente forma: el 55\% minusvalías físicas, 36\% sensoriales y el $9 \%$ psíquicas (Gil, 1999).

Salomone y Paige (1992) describen una serie de barreras en las personas con déficits. Estas son:

a) Una actitud negativa de la gente hacia la discapacidad y un desconocimiento de los potenciales y limitaciones que poseen las personas con discapacidades, incluidos los educadores y los propios asesores vocacionales.

b) Un pobre autoconocimiento. Suelen tener una baja autoestima y una actitud negativa hacia ellos mismos y sus posibilidades. En ocasiones, este hecho se produce por la excesiva protección familiar.

c) Una inadecuada planificación y preparación vocacional.

d) La propia discapacidad les limita las opciones.

c) Si además se tienen en cuenta las barreras con las que se topan a la hora de encontrar un puesto de trabajo se podrían añadir las siguientes:

e) La negativa de empresarios a contratarles.

f) La escasez y generalmente muy limitados medios de transporte que les podrían llevar al puesto de trabajo.

g) Los estudiantes con discapacidades sensoriales y motóricas suelen encontrarse con otros problemas que se unen a esas barreras y entre ellos destacamos los siguientes:

h) La crisis económica que suele haber en la mayoría de los países y que suele llevar consigo altas tasas de paro. i) La insensibilidad de la sociedad y de los propios educadores a la hora de tener en cuenta las necesidades de estos estudiantes de desarrollo de carrera y de desempeño de un adecuado trabajo.

j) La falta de conocimiento y de contacto personal con personas con discapacidad que han tenido éxito profesional y que les sirva de modelo.

k) La propia incertidumbre y confusión que ellos mismos poseen sobre su potencial vocacional.

1) Las actitudes de los propios asesores que insisten más, en el proceso de asesoramiento, en las dificultades y carencias que en las habilidades y potencial de desarrollo.

m) La falta de servicios adecuados para atender a estudiantes discapacitados tanto en el entorno escolar como en el laboral.

Por otra parte, tal y como señala Rocabert (1999), autores como De Mario (1992) indican una serie de criterios que los empresarios exigen en el momento de la selección de trabajadores con alguna minusvalía, así como a una serie de destrezas que poseen las personas que tienen éxito y satisfacción laboral. Aspectos que pasamos a desarrollar.

Los empresarios exigen:

a) Buenos hábitos de trabajo: responsabilidad, finalización de tareas, actitud positiva hacia el trabajo.

b) Capacidad de socialización: relaciones adecuadas con los trabajadores, supervisores, etc.

c) Capacidad de comunicación: saber escuchar y hablar adecuadamente.

d) Capacidad lectora y numérica básica.

Además, las características que poseen las personas con déficits que tienen éxito vocacio- 
nal son las que se aproximan a estas características:

a) Una actitud positiva hacia el trabajo.

b) Una actitud positiva hacia ellos mismos.

c) Metas vocacionales realistas.

d) Buenas capacidades de orientación y de movilidad.

e) Buenas capacidades de comunicación.

f) Alto nivel de independencia en la vida diaria.

g) Buenos niveles de integración en la Comunidad.

h) Un alto nivel de contactos sociales.

Finalmente, existen una serie de factores que suelen desconocer los estudiantes con déficits y necesidades educativas especiales de una serie de temas que les son propios tales como:

a) La legislación de su país que les afecta.

b) Los beneficios sanitarios de los que pueden disponer.

c) La existencia de Servicios de Asesoramiento tanto generales como específicos

d) Los programas y guías de asesoramiento vocacional existentes.

e) Su propio desarrollo de carrera.

f) La elaboración adecuada de cartas de presentación y del curriculum.

g) Las habilidades necesarias para la búsqueda de empleo.

h) Las acomodaciones necesarias a realizar tanto en el estudio como en el trabajo y en el ambiente laboral debido a su discapacidad.

i) Cuándo y cómo comunicar su discapacidad en un proceso de búsqueda de empleo.
Por lo que respecta a los centros educativos, podemos decir que, salvo diferencias, las finalidades que persiguen unos y otros se identifican, en última estancia, con la formación integral de la persona. Por otra parte, aunque las vías de acceso a esa formación son distintas en función de la institución en que nos encontremos, intentaremos situar líneas comunes de actuación que, en principio, son mejores que otras para educar en la diversidad y que marcan algunas directrices básicas que podrían servir de pauta para generar otros programas que pusieran en consideración la diversidad de los individuos participantes (Del Rincón, 1999).

a) En general, la oferta educativa variada es más conveniente porque se adapta, con más probabilidad a las características de los individuos y porque proporciona posibilidades de elección. Si en un centro de cultura, por ejemplo, se ofrecen actividades de teatro y de guiñol, los asistentes podrán optar por una de las dos actividades en función de sus habilidades, posibilidades psico-fisiológicas o del interés por adquirirlas.

b) El punto anterior supone conceder unos márgenes de autonomía a los individuos, así como una cierta flexibilidad horaria. El excesivo directivismo y la rigidez organizativa uniformizan. Los mensajes que siguen a continuación, contrastan por los efectos bien distintos que pueden provocar en los receptores:

"Tenéis veinte minutos para terminar los ejercicios 3, 4, 8, 10 y 23"

"Al final de esta semana nos comprometemos a realizar al menos 5 ejercicios del tema 5"

c) Es importante trabajar las actitudes y los valores, pero tienen una repercusión especial sobre la atención a la diversidad aquellos ejercicios que cultivan la capacidad para situarse en el punto de vista de los demás, que ayudan a comprender y a tolerar sus opiniones, sus formas de ser y de entender el mundo, etc. 
d) Todo educador de cualquier contexto debe fundamentar su trabajo en la atención personal. Así, las orientaciones dadas "para todos" adquieren significado preciso y propio para cada uno. Cuando un educador, al principio de su propuesta de actividades, invita a la participación, es escuchado igualmente por todos los asistentes. Será oportuno, no obstante, que matice su demanda general en función de las características de cada uno: los más tímidos y los que suelen mostrar afán de protagonismo, por ejemplo.

e) Fomentar lo que podríamos denominar la "pedagogía del éxito" o, en otras palabras, que el educador programe un porcentaje de actividades en cuya realización puedan tener éxito todas las diversidades existentes en el grupo al cual se dirige el programa. Para que esta condición se cumpla, convendrá respetar que cada uno siga su propio ritmo en las realizaciones.

f) Aprovechamiento del error para el crecimiento personal; sobre todo en aquellos casos en que el autoconcepto está situado bajo mínimos. En este punto podemos referenciar el siguiente hecho: los organizadores de un campamento de verano, muchos de ellos eran nuevos en este cometido y durante la preparación del mismo, se plantearon un paradójico lema de funcionamiento: "prohibido hacerlo bien". La intención era, justamente, provocar el efecto contrario, es decir, darse una buena dosis de confianza, a partir de la cual, el éxito sería más probable. Se trataba, en otras palabras, de perder el miedo a hacerlo mal y de hacerse conscientes de que los errores y desaciertos no debían menoscabar el ánimo.

g) La evaluación o las estrategias de seguimiento de las actividades para cualquier contexto deben ser de dos tipos: institucionales, globales, de grupo y también singulares para cada individuo, con la intención de considerar su evolución, expectativas, grado de esfuerzo, etc.

h) Ligado al punto anterior, si a alguien debe favorecer la acreditación de títulos, éste debe ser la persona discapacitada o aquélla para la cual será más complejo adquirir el mismo grado por otras vías paralelas y posteriores.

i) Educar en la diversidad debe ser un compromiso de todos los componentes, sin excepción, de un centro educativo. En este sentido, no debe haber un encargado específico del tema en cada institución sino que todos los educadores, todas las propuestas y la dinámica del centro en general deben tener en cuenta la diversidad de las personas, más aún, su diversidad concreta y específica

Aunque el listado podría prolongarse, queremos dejar claro que atender la diversidad debe ser compatible con una exigencia razonable. En este sentido, conviene insistir en la necesidad de que el educador conozca a sus educandos y el educando se autoconozca. Ambas condiciones han de favorecer el deseado equilibrio entre atención individual y demanda de unos resultados coherentes con los estadios de partida. Así, podrá darse la paradoja de felicitar a un estudiante universitario, a pesar del suspenso, y mostrar disconformidad con un notable, porque su capacidad de trabajo, de haberla aprovechado en su totalidad, hubiera alcanzado la máxima valoración.

\subsection{Ejemplificación de programas de intervención}

En este apartado se van a describir algunos de los programas de intervención que se vienen aplicando en los denominados grupos emergentes.

\subsubsection{Tercera edad}

En los últimos treinta años, la Unión Europea ha desarrollado políticas de intervención dirigidas, fundamentalmente, a la integración de los ancianos en la sociedad.

Concretamente en Castilla-La Mancha, a partir de 1998 se ha puesto en marcha el Plan de Atención a las Personas Mayores (1998-2002) (Martínez, 1999). Dicho plan pretende abordar los problemas de las personas mayores de forma integral. Además de atender las necesidades 
Bayot, A., Rincón, B. Del y Hernandez Pina, F. (2002): Orientación y atención a la diversidad: descripción de programas y acciones en algunos grupos emergentes . RELIEVE:, v. 8, n. 1, p. 66-87.

http://www.uv.es/RELIEVE/v8n1/RELIEVEv8n1_2.htm

básicas, también se pretenden desarrollar nuevas formas de intervención sociosanitaria, así como fomentar su autonomía. En líneas generales, el Plan de Atención a las Personas Mayores en Castilla-La Mancha se basa en los siguientes criterios: a) enfoque integral para atender las necesidades de las personas mayores; b) coordinación eficaz entre las Administraciones Públicas; c) colaboración con la iniciativa social (O.N.G., etc.); d) racionalización en la utilización de los recursos disponibles; y e) favorecer la máxima integración y normalización en su entorno social habitual. Promover el asociacionismo y la participación activa de las iniciativas para la realización de actividades organizadas por las personas mayores.

\subsubsection{Inmigrantes}

Entre los programas dirigidos a fomentar la educación intercultural, se puede mencionar el modelo EUROSUR (Bayot y Garcés, 2001; Garcés, Bayot, Ródenas, Sánchez y Verdeguer, 2000), los trabajos llevados a cabo por el grupo GREDI (Bartolomé et al., 1999), los materiales elaborados por el grupo Asklepios / Cronos (Martín y Gutiérrez, 1993), el modelo de intervención para favorecer la adaptación escolar en contextos inter-étnicos (Díaz-Aguado y Baraja, 1993), etc.

Concretamente, el modelo EUROSUR se encuentra entre el modelo holístico de Banks y Linch (1986), ya que dicho programa de intervención se aplica en la propia institución escolar, incorporando modelos heurísticos no racistas, y el anti-racista, desde una perspectiva global. Es más, el modelo EUROSUR va más allá que el anti-racista, ya que es capaz de integrar la acción curricular del sistema educativo y la acción social desarrollada por organizaciones de apoyo a los inmigrantes. Su aplicación deberá contar con el apoyo de las administraciones públicas, especialmente las educativas, y de la iniciativa social implicada directamente en el trabajo con emigrantes. Bajo estas premisas se crea y se desarrolla en España el modelo EUROSUR. En líneas generales, consta de 4 fases y se aplica en parti- cipantes con edades comprendidas entre $15 \mathrm{y}$ 20 años en contextos educativos [4].

Además del cambio de actitudes racistas por otras más tolerantes, otro aspecto de especial preocupación se centra en la escolarización de los hijos de inmigrantes. Concretamente en la Comunidad de Castilla-La Mancha, desde 1998 se viene desarrollando una investigación dirigida a analizar hasta qué punto la procedencia cultural determina respuestas diferenciadas en variables relacionadas con el proceso educativo del individuo (Bayot, del Rincón y Navarro, 2000). Además, en la actualidad se está aplicando un programa de intervención para optimizar las deficiencias detectadas

en una serie de variables (clima social en la escuela, autoconcepto, socialización, etc.), con la finalidad de conformar unos perfiles relativos a las necesidades que presentan los alumnos de las minorías étnicas, y que sirvan de orientación y de apoyo a los profesionales de la educación en su labor docente [5].

\subsubsection{Discapacidades [6]}

Díaz-Aguado (1995) ha desarrollado el "Programa de Aprendizaje Cooperativo para Contextos de Integración" (PACCI), para niños con algún tipo de discapacidad. El aprendizaje cooperativo es diametralmente opuesto al aprendizaje competitivo, es decir que aprender cooperativamente supone que el éxito de cada uno de los componentes del grupo se produce si y sólo si el resto de los compañeros también tienen éxito. Para esta autora, un aprendizaje de tales características contribuye a integrar a los alumnos con necesidades educativas especiales ya que cada sujeto puede trabajar según sus posibilidades, se produce un óptimo nivel de éxito, suele favorecer la autoestima y promueve las relaciones interpersonales.

El programa mencionado (Díaz-Aguado, 95) consiste en introducir el aprendizaje cooperativo como actividad académica regular, aunque compartida con otras formas de trabajo. Se practica progresivamente, empezando con una materia (dos o tres sesiones a la semana de 45 
o 60 minutos). Los resultados comienzan a ser significativos al cabo de unas 16 sesiones.

Debe comenzarse por una asignatura que presente pocos problemas para los alumnos con dificultades y las tareas suelen descomponerse en unidades fáciles de manejar. Los equipos suelen ser de entre 4 y 6 alumnos, heterogéneos y conviene que se dé una cierta empatía entre sus componentes.

Por otra parte, desde los años sesenta, como consecuencia de las técnicas de modificación de conducta para niños autistas, se han propuesto programas para favorecer la comunicación, el lenguaje y las competencias sociales (Rivière, 1996), por ejemplo, los métodos propuestos por Ivar Lovaas para la enseñanza de conductas verbales.

Actualmente, sin embargo, la tendencia consiste en utilizar sistemas funcionales: desarrollo de la comunicación con códigos alternativos, enfoque positivo de la comunicación como medio para conseguir cosas, etc. Algunos de los instrumentos actuales utilizados para favorecer la comunicación son:

El método TEACCH que es una guía de objetivos y actividades con sugerencias para su programación y evaluación. Desarrollar habilidades comunicativas en contextos naturales.

El programa de Comunicación Total de Schaeffer. El terapeuta utiliza signos y palabras a la vez (bimodal), de manera que enfatiza la vertiente expresiva del lenguaje, siempre desde una perspectiva funcional (Schaeffer y otros, 1980).

Éstos son solamente dos recursos de los muchos que se pueden utilizar para estimular el desarrollo de los niños autistas. Según Rivière (1996), "es necesaria la intervención activa de todas las comunidades del niño (familia, centro escolar, profesorado, compañeros si es posible) y no solamente del terapeuta..." (pp. 64-65).

Los alumnos con discapacidad motriz presentan, a menudo, trastornos sensoriales asociados y, por tanto, además de las correspondientes adaptaciones, precisan apoyos específicos: físico o motriz, verbal, visual, etc. La comunicación puede favorecer con estrategias concretas como el Juego Intensivo y el citado Programa de la Comunicación Total. Sobre estos temas, se puede encontrar amplia información, por ejemplo, en Basil, Bolea y Soro (1996). Quizá conviene destacar también los programas de ayuda a las familias cuyos hijos están afectados por algún tipo de discapacidad importante. Desarrollan funciones informativas, de formación, prevención, asesoramiento y apoyo personal. Intentan desarrollar contextos colaborativos, habilidades y estrategias a llevar a cabo en el mismo hogar (Basil y otros, 1996).

La tarea psicopedagógica en los casos de discapacidad auditiva y visual graves consiste en realizar una valoración adecuada y encontrar las respuestas educativas más adecuadas $\mathrm{y}$ normalizadas posible. Para ello, el psicopedagogo tendrá que identificar los recursos existentes en el sector, asesorar a los centros que acojan a estos alumnos y, especialmente, al profesorado que lleve a cabo actuaciones directas. También apoyará la labor educativa de las familias, así como la aceptación positiva de la situación.

\subsubsection{Dependencias a sustancias adicti- vas}

Las actuaciones preventivas han de realizarse a través de "programas", con la implicación de diversos organismos, tanto públicos como privados. Diseñar actividades aisladas o puntuales suele tener un valor limitado.

Con relación a los programas de prevención del tabaquismo en niños y adolescentes, Brink y colaboradores (1988) citan seis componentes que debe considerar una escuela en la elección de un programa para prevenir el inicio del comportamiento adictivo al tabaquismo, y que pasamos a enumerar de forma resumida: a) un componente informativo; b) un componente de entrenamiento en habilidades sociales; c) un componente en el que los alumnos se compro- 
Bayot, A., Rincón, B. Del y Hernandez Pina, F. (2002): Orientación y atención a la diversidad: descripción de programas y acciones en algunos grupos emergentes . RELIEVE:, v. 8, n. 1, p. 66-87.

http://www.uv.es/RELIEVE/v8n1/RELIEVEv8n1_2.htm

metan públicamente exponiendo sus razones para no fumar; d) el uso de estrategias de aprendizaje que incluyan métodos de aprendizaje eficaz; y e) utilización de compañeros de los alumnos como líderes; y f) que el programa contemple sesiones de seguimiento para mantener los efectos del programa.

En nuestro entorno, entre los programas de prevención del tabaco ${ }^{[7]} \mathrm{y}$ del alcohol centrados en la escuela, se puede mencionar la experiencia llevada a cabo por el CEIP "Alfred Potrony" de Térmens (Lérida) (Bañeres, 1996) ${ }^{[8]}$. Con relación a los programas de intervención, la Terapia de Auto-Regulación Emocional ha mostrado su eficacia tanto al final del tratamiento como en los seguimientos realizados (Bayot, 1994; Bayot, Capafons y Amigó, 1995; Bayot, Capafons y Cardeña, 1997).

Por otra parte, respecto de los programas de prevención de las toxicomanías que se propug- nan desde la FAD (1999), se basan en los siguientes aspectos: a) una prevención concebida como educación en valores, competencias y habilidades sociales; b) una prevención que precisa de la evaluación y el rigor metodológico; c) una prevención que parte de la articulación de estrategias globales coordinadas; d) una prevención universal que trata de hacerse compatible con la priorización de los grupos de alto riesgo; y e) una prevención que sólo puede llevarse a cabo mediante el fomento de la participación de toda la sociedad.

A continuación se describen los programas que la FAD (1999) desarrolla. En estos programas se aporta un repertorio de los mismos y la forma de acceder a su utilización, así como a los distintos elementos y materiales que los apoyan, con el fin de que puedan ser fácilmente utilizados. Estos son:

1. PLAN INTEGRAL DE PREVENCIÓN ESCOLAR (PIPES).

2. TÚ Y LA MÚSICA.

3. EL VALOR DE UN CUENTO.

4. CINE Y EDUCACIÓN DE VALORES.

5. PROGRAMA DE FAMILIAS.

6. PROGRAMA DE JOVENES.

7. VOLUNTARIADO.

8. MEDIADORES SOCIALES / JUVENILES.

9. PREVENCIÓN LABORAL.

10. ACTIVIDAD INTERNACIONAL.

\subsubsection{Infección por VIH / SIDA}

Respecto de los programas de intervención del VIH/SIDA, el entrenamiento en habilidades cognitivo-comportamentales necesarias para evitar las conductas de riesgo podrían darse en las siguientes áreas (Ballester, 1997): a) sexo seguro; b) seguridad al inyectarse drogas; c) asertividad para comunicar el deseo sexual seguro y resistir coerciones; d) habilidades de automanejo y solu- ción de problemas para anticipar, evitar y desarrollar métodos alternativos para manejar los desencadenantes de los riesgos; y e) refuerzo por los esfuerzos realizados en el cambio comportamental.

\section{Bibliografía}


Bayot, A., Rincón, B. Del y Hernandez Pina, F. (2002): Orientación y atención a la diversidad: descripción de programas y acciones en algunos grupos emergentes . RELIEVE:, v. 8, n. 1, p. 66-87.

http://www.uv.es/RELIEVE/v8n1/RELIEVEv8n1_2.htm

Aguado, T., Gil, J. A., Jiménez-Frías, R. A. y Sacristán, A. (1999). Diversidad cultural e igualdad escolar. Un modelo para el diagnóstico y desarrollo de actuaciones educativas en contextos escolares multiculturales. Revista de Investigación Educativa, 17, 2, 471-475.

Asociación para la Lucha Contra las Enfermedades Renales (ALCER, 1997). Estudio sobre "Calidad de vida del paciente en diálisis".

Ballester, R. (1997). Intervención psicológica en SIDA y VIH: Prevención y tratamiento. En L. M. Pascual y R. Ballester (dirs.), La práctica de la psicología de la salud. Valencia: Promolibro.

Banks, J. A. \& Linch, J. (1986). Multicultural education in the western societies. London: Holt, Rinehart and Winston.

Bañeres, D. (1996). Contra el tabaco y el alcohol. Cuadernos de Pedagogía, 247, 34-37.

Bartolomé, M., Cabrera, F., Del Campo, J., Espín, J. V., Marín, M. A., Rodríguez, M., Sandín, M. P. y Sabariego, M. (1999). Líneas de investigación del grupo de investigación en educación intercultural (GREDI). Revista de Investigación Educativa, 17, 2, 463-469.

Bartolomé, M., Cabrera, F., Espín, J. V., Marín, A. y Rodríguez, M. (1999). Diversidad y multiculturalidad. Revista de Investigación Educativa, 17 (2), 277-319.

Basil, C. (1996). Sistemas y ayudas técnicas de comunicación para personas con parálisis cerebral. En M. Poyuelo, P. Poo, C. Bail, y M. Le Métayer (coords.), Logopedia en la parálisis cerebral. Diagnóstico y tratamiento. Barcelona: Masson.

Basil, C., Bolea, E. y Soro-Camats, E. (1996). La discapacitat motriu. En Giné, C. (coord.). Trastorns del desenvolupament i necessitats educatives especials. Barcelona: UOC.

Bayot, A. (1994). Terapia de auto-regulación para la eliminación del tabaquismo. Tesis Doctoral. Facultat de Psicología. Universitat de València (Tesis publicada en microficha, 1998).

Bayot, A. (1998). Factores de riesgo en la etapa de iniciación en la conducta adictiva al tabaco. Mexican Journal of Behavior Analysis, 24, 1741.

Bayot, A., Capafons, A. y Amigo, S. (1995). Tabaco y Terapia de Auto-Regulación Emocio- nal: Un programa estructurado para dejar de fumar. Valencia: Promolibro.

Bayot, A., Capafons, A. \& Cardeña, E. (1997). Emotional Self-Regulation Therapy: A New and Efficacious Treatment for Smoking. American Journal of Clinical Hypnosis, 40, 2, 146156.

Bayot, A., del Rincón, B. y Navarro, M. J. (2000). Inmigración e integración social en la enseñanza secundaria. Comunicación presentada en el Symposium sobre Medición organizado por el Departamento de MIDE de la Facultad de Filosofía y CC. de la Educación de la Universidad de Valencia (pendiente de publicación).

Bayot, A., del Rincón, B., Racionero, C. F. y González, S. (2000). Resultados preliminares de un servicio de orientación universitaria en Castilla-La Mancha. En G. Salmerón y V. L. López (coords.), Orientación educativa en las universidades. Granada: Grupo Editorial Universitario.

Bayot, A. y Garcés, J. (coords.)(2001). La educación intercultural a través del modelo EUROSUR. Cuenca: Servicio de Publicaciones de la Universidad de Castilla-La Mancha.

Bayot, A. \& Mari, B. (1998). Heterosexual behaviour and attitudes towards the risks of contracting HIV/AIDS. In J. J. Borrás \& M. Pérez (coords.), Sexuality and human rights. Valencia: NAU Llibres.

Bayot, A., Navarro, M.J. y Del Rincón, B. (2000). Situación sociolaboral de los inmigrantes extranjeros en España. En J. Cajide, M. A. Santos y A. Porto (eds.), Calidad y empleo en contextos multiculturales. Santiago de Compostela: Servicio de Publicaciones de la Universidad de Santiago de Compostela.

Beltrán, J. (1993). Procesos, estrategias y técnicas de aprendizaje. Madrid: Síntesis.

Beltrán, J., Bermejo, V., Prieto, M. D. y Vence, D. (1993). Intervención psicopedagógica. Madrid: Pirámide.

Brown, L. K. y Fritz, G. K. (1988). Children's knowledge and attitudes about AIDS. Journal of American Academy of Child Adolescent Psychiatry, 27, 504-508.

Brink, S. G., Simons-Morton,, D. G., Harvey, C. M. Parcel, G. S. y Tiernan, K. M. (1988). 
Bayot, A., Rincón, B. Del y Hernandez Pina, F. (2002): Orientación y atención a la diversidad: descripción de programas y acciones en algunos grupos emergentes . RELIEVE:, v. 8, n. 1, p. 66-87.

http://www.uv.es/RELIEVE/v8n1/RELIEVEv8n1_2.htm

Developing comprehensive smoking control programs in schools. Journal of School Health, $58,5,177-180$.

Cahuzac, M. (1985). El niño con trastornos motores de origen cerebral. Buenos Aires: Ed. Médica Panamericana.

Centro Nacional de Epidemiología (C.N.E., 1999). Vigilancia epidemiológica del SIDA en España. Instituto de Salud Carlos III. Ministerio de Sanidad y Consumo. Informe Trimestral, $\mathrm{N}^{\mathrm{o}}$ 3.

Craik, F. I. M. y Jennings, J. M. (1992). Human memory. En Craik, F. I. M. y Salhouse, T. A. (eds.), The handbook of aging and cognition. New Jersey: LEA.

De Mario, N. (1992). Skills need for successful employment: a review of the literature. Review, 24, 3, 115-125.

Del Rincón, B. (1998). El psicopedagog en el centre de Secundària: sugeriments $\mathrm{y}$ propostes. Barcelona: Estel.

Del Rincón, B. (1999). La atención a la diversidad como indicador de calidad en educación: su práctica y su orientación. Comunicación presentada en el Congreso Internacional de Calidad Educativa, Empleo e Interculturalismo en el Camino de Santiago. Santiago de Compostela, 2-4 de septiembre de 1999.

Del Rincón, B., Bayot, A., García, A. y Argudo, S. (2000). El Servicio de Orientación Universitaria de Cuenca: justificación y trayectoria. En G. Salmerón y V. L. López (coords.), Orientación educativa en las universidades. Granada: Grupo Editorial Universitario.

Delors, J. (1996). La educación encierra un tesoro. Informe a la UNESCO de la Comisión Internacional para el siglo XXI. Madrid: Santillana.

Díaz-Aguado, M. J. (1995). Programas para favorecer la integración escolar: Manual de intervención. Madrid: ONCE.

Díaz-Aguado, M. J. y Baraja, A. (1993). Interacción educativa y desventaja sociocultural: Un modelo de intervención para favorecer la adaptación escolar en contextos inter-étnicos. Madrid: C.I.D.E.

Díez, J. (dir.) (1998). Las actitudes de la sociedad española hacia los inmigrantes. Madrid: IMSERSO.
Echeita, G. (coord.) (1997). Atenció a la diversitat i necessitats educatives especials. Barcelona: UOC.

Ferrer, A. y Alcantud, F. (1999). Asesoramiento pedagógico en estudiantes con discapacidades motóricas. En F. Rivas y M. L. López (coords.), Asesoramiento vocacional de estudiantes con minusvalías físicas y sensoriales. Valencia: Servei de Publicacions de la Universitat de València.

Fundación de Ayuda contra la Drogadicción (FAD, 1997). Encuesta domiciliaria sobre consumo de drogas.

Garcés, J., Bayot, A., Ródenas, F., Sánchez, S. y Verdeguer, I. (2000). El modelo EUROSUR como metodología de activación de la interculturalidad. En J. Cajide, M. A. Santos y A. Porto (eds.), Calidad y empleo en contextos multiculturales. Santiago de Compostela: Servicio de Publicaciones de la Universidad de Santiago de Compostela.

Gil, J. (1999). Asesoramiento vocacional, información e intervención con estudiantes con minusvalías físicas y sensoriales. En F. Rivas y M. L. López (coords.), Asesoramiento vocacional de estudiantes con minusvalías físicas y sensoriales. Valencia: Servei de Publicacions de la Universitat de València.

INSERSO (1993). Plan gerontológico nacional. Madrid: INSERSO.

Instituto Nacional de Estadística (INE) (1992). Avance del censo de población de 1991. Madrid: INE.

Ishii-Kuntz, M. (1990). Social interaction and psychological well-being: comparison across stages of adulthood. International Journal of Aging and Human Development, 30, (1), 1536.

Jordán, J. A. (1998). Multiculturalisme y educació. Barcelona: UOC / Proa.

Lando, H. A. (1991). Toward a comprehensive strategy for reducing the health burden tobacco. British Journal of Addiction, 86, 649-652.

Marchesi, Á. y Díaz-Estébanez, E. (1997). Discapacitat auditiva. Barcelona: Edicions de la Universitat Oberta de Catalunya.

Martín, A. y Gutiérrez, B. (1993). La situación de los extranjeros como objeto de estudio en un Proyecto Curricular. Documento polico- 
Bayot, A., Rincón, B. Del y Hernandez Pina, F. (2002): Orientación y atención a la diversidad: descripción de programas y acciones en algunos grupos emergentes . RELIEVE:, v. 8, n. 1, p. 66-87.

http://www.uv.es/RELIEVE/v8n1/RELIEVEv8n1 2.htm

piado. Presentado en el encuentro de trabajo del CIDE, 8-9 de febrero. Madrid.

Martínez, J. L. (1999). Plan de atención a mayores de la Comunidad de Castilla-La Mancha. En S. Yubero, J. M. Latorre, J. Montañés y E. Larrañaga (coords.), Envejecimiento, sociedad y salud. Cuenca: Servicio de publicaciones de la Universidad de Castilla-La Mancha.

Parcerisa, A. (1999). Didáctica en la educación social. Enseñar y aprender fuera de la escuela. Barcelona: Graó.

Pelechano, V. et al. (1995). Las personas con deficiencias visuales. En M. Verdugo (coord.), Personas con discapacidad. Perspectivas psicopedagógicas y rehabilitadoras. Madrid: Siglo XXI.

Repetto, E. (1999). Orientación y sociedad. Revista de Investigación Educativa, 17, 2, 581586.

Rivas, F. (1999). Conducta, asesoramiento vocacional y minusvalía. En F. Rivas y M. L. López (coords.), Asesoramiento vocacional de estudiantes con minusvalías físicas y sensoriales. Valencia: Servei de Publicacions de la Universitat de València.

Rivière, A. (1996). L'autisme. En Giné, C. (coord.). Trastorns del desenvolupament i necessitats educatives especials. Barcelona: UOC.

Rocabert, E. (1999). Problemática y desarrollo vocacional de los estudiantes con minusvalías sensoriales y motóricas. En F. Rivas y M. L. López (coords.), Asesoramiento vocacional de estudiantes con minusvalías físicas y sensoriales. Valencia: Servei de Publicacions de la Universitat de València.

Salomone, P. R. \& Paige, R. E. (1992). Employement problems and solutions: perceptions of blind and visually impaired adults. Vocational Guidance Quarterly, 33, 147-156.

Schaeffer, B.: Musil, A.; Kollizas, G. (1980). Total communication. Illinois: Research Press.

Soriano, E., Moreno, Y., Collado, B. y Martín, E. (1999). Educación multicultural en tierra de migraciones: El caso de Almería. Revista de Investigación Educativa, 17, 12, 477-482.

Steptoe, A., Wardie, J., Smith, H., Koop, M., Skrabski, A., Vinck, J. \& Zotti, A. (1995). Tobacco smoking in young adults from 21 euro- pean countries: Association with attitudes and risk awareness. Addiction, 90, 571-582.

Vega, J. L. y Bueno, B. (1995). Desarrollo adulto y envejecimiento. Madrid: Síntesis

Villalba, A. (1999). Conducta y asesoramiento vocacional de estudiantes con discapacidad auditiva. En F. Rivas y M. L. López (coords.), Asesoramiento vocacional de estudiantes con minusvalías físicas y sensoriales. Valencia: Servei de Publicacions de la Universitat de València.

\section{NOTAS}

[1] Como ejemplo, podemos citar el SIL (Servicio de Integración Laboral) de Cuenca, por su magnífica labor de apoyo a la integración laboral de personas discapacitadas.

[2] No obstante, la orientación también se requiere en el campo de las organizaciones, de lo social, del tiempo libre, de las personas mayores, etc. (Repetto, 1999).

[3] Ver, por ejemplo, Programa d'intervenció en habilitats adaptatives del centre ocupacional Bogatell. Generalitat de Catalunya, Icaria Editorial, 1999.

[4] El programa de intervención basado en el modelo EUROSUR, se describe con detalle en Bayot y Garcés (2001).

[5] Los proyectos de investigación "El reto de la educación intercultural: algunos aspectos psicológicos, sociales y educativos de las minorías étnicas en Castilla-La Mancha" (1999) e "Intervención psicopedagógica en alumnos de minorías culturales en Castilla-La Mancha" (2000), han sido subvencionados por la Universidad de CastillaLa Mancha, siendo el investigador principal $\mathrm{M}^{\mathrm{a}}$ José Navarro García.

[6] Es digna de mención la labor realizada por la Unitat d'Investigació ACCESO, del Departament de Psicologia Evolutiva i de l'Educació de la Universitat de Valencia, con relación a la integración e inserción socio-laboral de personas con discapacidades físicas y/o sensoriales.

[7] En un contexto universitario, el Instituto de Investigación de Drogodependencias (INID), de la Universidad Miguel Hernández, está llevando a cabo el Taller para dejar de fumar "Dale la espalda al tabaco".

[8] Para una revisión de los factores que intervienen en el inicio del comportamiento adictivo al tabaco, consultar Bayot (1998). 
Bayot, A., Rincón, B. Del y Hernandez Pina, F. (2002): Orientación y atención a la diversidad: descripción de programas y acciones en algunos grupos emergentes . RELIEVE:, $v .8$, n. 1, p. 66-87.

http://www.uv.es/RELIEVE/v8n1/RELIEVEv8n1 2.htm

\section{ABOUT THE AUTHORS / SOBRE LOS AUTORES}

Agustín Bayot Mestre (Agustin.Bayot@uclm.es): Profesor Titular del área de Métodos de Investigación y Diagnóstico en Educación de la Universidad de Castilla- La Mancha ( UCLM). Entre sus líneas de trabajo se encuentran atención a la diversidad, educación para la salud, validación de instrumentos de medida, procesos de aprendizaje, intervención psicológica y orientación universitaria. Su dirección postal es : Facultad de Ciencias de la Educación y Humanidades. Universidad de Castilla-La Mancha. Avda. de los Alfares, 44. 16002 Cuenca (España). Teléfono. (34) 969179100.

Benito del Rincón Igea (B.Rincon@uclm.es): Profesor Titular de la Facultad de CC de la Educación y Humanidades de la UCLM. Posee una amplia experiencia en formación inicial y permanente del profesorado y algunos de sus ámbitos de estudio se relacionan con la atención a la diversidad y el trabajo psicopedagógico. Sobre estos temas ha publicado varias obras y artículos de revista.

Fuensanta Hernádez Pina (fhpina@um.es): Catedrática del Departamento de Métodos de Investigación y Diagnóstico en Educación de la Universidad de Murcia. Su dirección postal es Facultad de Educación. Universidad de Murcia. Campus Universitario de Espinardo. 30100 Murcia (España). Entre las líneas de trabajo en las que ha desarrollado una mayor actividad en los últimos años, cabe resaltar enfoques y estilos de aprendizaje y evaluación institucional. Ha publicado un gran número de libros y artículos en revistas especializadas.

\section{ARTICLE RECORD / FICHA DEL ARTÍCULO}

\begin{tabular}{|c|c|}
\hline $\begin{array}{l}\text { Reference / } \\
\text { Referencia }\end{array}$ & $\begin{array}{l}\text { Bayot, A., del Rincón, B. y Hernández Pina, F. (2002). Orientación y atención a la diversi- } \\
\text { dad: descripción de programas y acciones en algunos grupos emergentes. Revista ELectró- } \\
\text { nica de Investigación y EValuación Educativa, v. 8, n. } 1 \text {. } \\
\text { http://www.uv.es/RELIEVE/v8n1/RELIEVEv8n1 2.htm. Consultado en (poner fecha). }\end{array}$ \\
\hline Title / Título & $\begin{array}{l}\text { Orientación y atención a la diversidad: descripción de programas y acciones en algunos gru- } \\
\text { pos emergentes [Counseling and attention to the diversity: description of programs and ac- } \\
\text { tions in some emergent groups] }\end{array}$ \\
\hline Authors / Autores & Agustín Bayot, Benito del Rincón y Fuensanta Hernández Pina \\
\hline $\begin{array}{l}\text { Review / } \\
\text { Revista }\end{array}$ & Revista ELectrónica de Investigación y EValuación Educativa (RELIEVE), v. 8, n. 1 \\
\hline ISSN & 4032 \\
\hline $\begin{array}{l}\text { Publication date / } \\
\text { Fecha de publica- } \\
\text { ción }\end{array}$ & 2002 (Reception Date: 24 January 2002; Publication Date: 20 May 2002) \\
\hline $\begin{array}{l}\text { Abstract / } \\
\text { Resumen }\end{array}$ & $\begin{array}{l}\text { This article offers points for reflection, practical elements and criteria for adoption in rela- } \\
\text { tion to addressing diversity and its orientation. Formal and informal contexts are dealt with } \\
\text { from a social and educational perspective; the diversity which can be found in the ordinary } \\
\text { population and those included within the so called "emerging groups" are also focused on. } \\
\text { Within this framework the function of the educational psychologist lies not only in knowing } \\
\text { the basic characteristics of the groups which most represent diversity and in evaluating spe- } \\
\text { cific situations, but also in bringing solutions to the problems specific to each group, both as } \\
\text { individuals and as a collective, by means of the creation and application of programmes of } \\
\text { intervention. Our contribution concentrates on describing the problems presented by certain } \\
\text { groups and proposing effective plans for action. }\end{array}$ \\
\hline
\end{tabular}


Bayot, A., Rincón, B. Del y Hernandez Pina, F. (2002): Orientación y atención a la diversidad: descripción de programas y acciones en algunos grupos emergentes . RELIEVE:, v. 8, n. 1, p. 66-87.

http://www.uv.es/RELIEVE/v8n1/RELIEVEv8n1_2.htm

\begin{tabular}{|c|c|}
\hline & $\begin{array}{l}\text { Este artículo quiere ofrecer líneas de reflexión, criterios a seguir y elementos prácticos } \\
\text { acerca de la atención a la diversidad y a su orientación. La temática se abordará desde una } \\
\text { perspectiva social y escolar, contemplando a la vez contextos educativos formales y no forma- } \\
\text { les y atendiendo "las diversidades" que podemos encontrar en la población ordinaria y las que } \\
\text { se podrían incluir bajo el epígrafe de "grupos emergentes". } \\
\text { En este marco, la función del psicopedagogo no sólo radica en conocer las características } \\
\text { básicas de los grupos más representativos que conforman la diversidad y en evaluar situacio- } \\
\text { nes concretas sino fundamentalmente en aportar soluciones a los problemas relativos a cada } \\
\text { grupo, tanto de forma individual como colectivamente, por medio de la elaboración y aplica- } \\
\text { ción de programas de intervención. Nuestra aportación se centrará en describir la problemática } \\
\text { que presentan determinados colectivos así como en plantear líneas de actuación eficaces. }\end{array}$ \\
\hline $\begin{array}{l}\text { Keywords } \\
\text { Descriptores }\end{array}$ & $\begin{array}{l}\text { Addressing diversity, emerging groups, counselling, programmes of intervention } \\
\text { Atención a la diversidad, grupos emergentes, orientación, programas de intervención. }\end{array}$ \\
\hline $\begin{array}{l}\text { Institution / } \\
\text { Institución }\end{array}$ & University of Castilla-La Mancha, University of Murcia (Spain) \\
\hline $\begin{array}{l}\text { Publication site / } \\
\text { Dirección }\end{array}$ & http://www.uv.es/RELIEVE \\
\hline Language / Idioma & Español (Title, abstract and keywords in english) \\
\hline
\end{tabular}

\section{Revista ELectrónica de Investigación y EValuación Educativa (RELIEVE)}

\section{[SSN: 1134-4032 ]}

(C) Copyright 2002, RELIEVE. Reproduction and distribution of this articles it is authorized if the content is no modified and their origin is indicated (RELIEVE Journal, volume, number and electronic address of the document).

// C Copyright 2002, RELIEVE. Se autoriza la reproducción y distribución de este artículo siempre que no se modifique el contenido y se indique su origen (RELIEVE, volumen, número y dirección electrónica del documento). 